\section{Polymer Systems}

\section{0-24 June 2005, St. Petersburg, Russia}

The Institute of Macromolecular Compounds of the Russian Academy of Sciences continues its series of St. Petersburg meetings on macromolecules. The 5th International Symposium on Molecular Mobility and Order in Polymer Systems will be held in St. Petersburg, Russia, 20-24 June 2005.

The main objective of this IUPAC-sponsored Symposium is to discuss the modern problems of physics and chemistry in polymer systems with "soft" order preserving a pronounced molecular mobility. As during the 3rd Symposium, the focus will be on dynamic properties. Equilibrium problems will also be discussed. Experimental data as well as the results of theories and simulation approaches will be presented.
The symposium topics are as follows:

- macromolecules in solutions, melts and networks oriented and stretched in strong external fields

- liquid crystalline polymers

- copolymers and polymer blends

- polymer layers and micelles

- polymer complexes and membranes

- polymer networks of different topologies, branched and star polymers, dendrimers

The symposium program will include plenary lectures, 20 invited lectures, several 15-minute oral communications, and poster sections.

See Mark Your Calendar on page 43 for contact information

Siil, www.macro.ru

\section{Organic Solids}

\section{0-15 July 2005 \\ Cargese, Corsica, France}

Organic materials and polymers for electronics and optoelectronics represent a rapidly growing field of research with large impact for knowledge, technology and the economy, as well as for the environment. The conference Electrical and Related Properties of Organic Solids 2005 will be held 10-15 July 2005 in Cargese, Corsica, France.

The conference (ERPOS 2005) is the 10th following the tradition of the ERPOS conferences held since 1974. For this new edition, approximately 100 participants will be presented with 2 plenary lectures, 10

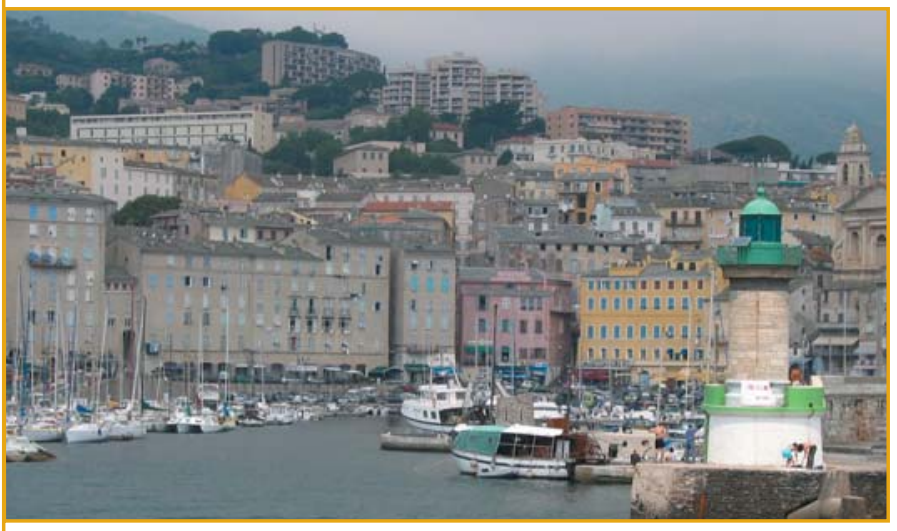

invited presentations, 3 poster sessions, 2 round tables and 20 special lectures. The meeting will provide an interdisciplinary forum for scientists working in the fields of molecular materials, low dimensional systems, molecular switchable solids, bio-polymers, environmentally friendly chemicals and "green" functional materials for electronics, electrical properties of organic and macromolecular systems, linear and nonlinear optical properties of organic and polymeric structures, data storage, electroluminescent and photovoltaic devices.

Our objectives are to achieve international cooperation of researchers both in academia and industry and to stimulate growth in the field of organic materials for electronics and photonics. A particular attention will be paid to the attendance of young researchers who will receive will receive registration discouts.

The conference will be held in the Institut d'Etudes Scientifiques de Cargèse <www.iesc.univ-corse.fr>, which is a modern conference venue, located in a small traditional village on the coast of the mediterranean island of Corsica. The conference fee is $€ 250$ including lunch, banquet, and excursions. There is a $10 \%$ reduction for IUPAC members.

\section{See Mark Your Calendar on page 43 for contact information.}

Siir http://sciences.univ-angers.fr/erpos/ 